\title{
Study of Coal Structure Using Secondary Ion Mass Spectrometry
}

\author{
G. L. Tingey \\ J. M. Lytle \\ D. R. Baer \\ M. T. Thomas
}

December 1980

Prepared for the U.S. Department of Energy under Contract DE-AC06-76RLO 1830

Pacific Northwest Laboratory Operated for the U.S. Department of Energy by Battelle Memorial Institute 
NOTICE

This report was prepared as an account of work sponsored by the United States Government. Neither the United States nor the Department of Energy, nor any of their employees, nor any of their contractors, subcontractors. or their employees, makes any warranty, express or implied, or assumes any legal liability or responsibility for the accuracy, completeness or usefulness of any information, apparatus, product or process disclosed, or represents that its use would not infringe privately owned rights.

The views, opinions and conclusions contained in this report are those of the contractor and do not necessarily represent those of the United States Government or the United States Department of Energy.

\title{
PACIFIC NORTHWEST LABORATORY
}

operated by

BATTELLE

for the

UNITED STATES DEPARTMENT OF ENERGY

Under Contract DE-AC06-76RLO 1830

\author{
Printed in the United States of America \\ Available from \\ National Technical Information Service \\ United States Department of Commerce \\ 5285 Port Royal Road \\ Springfield, Virginia 22151
}

Price: Printed Copy $\$$ $\therefore$ Microfiche $\$ 3.00$

NTIS

-Pages Selling Price

001-025 $\quad \$ 4.00$

026-050 $\$ 4.50$

$051-075 \quad \$ 5.25$

$076-100 \quad \$ 6.00$

$101-125 \quad \$ 6.50$

$126-150 \quad 57.25$

$151-175 \quad \$ 8.00$

$176-200 \quad \$ 9.00$

$201-225 \quad 59.25$

$226-250 \quad 59.50$

$251.275 \quad \$ 10.75$

$276.300 \quad \$ 11.00$ 


\section{9}

STUDY OF COAL STRUCTURE USING

SECONDARY ION MASS SPECTROMETRY

G. L. Tingey

J. M. Lytle

D. R. Baer

M. T. Thomas

December 1980

Prepared for the U.S. Department of Energy under Contract DE-ACO6-76RLO 1830

Pacific Northwest Laboratory Richland, Washington 9935 ? 


\section{CONTENTS}

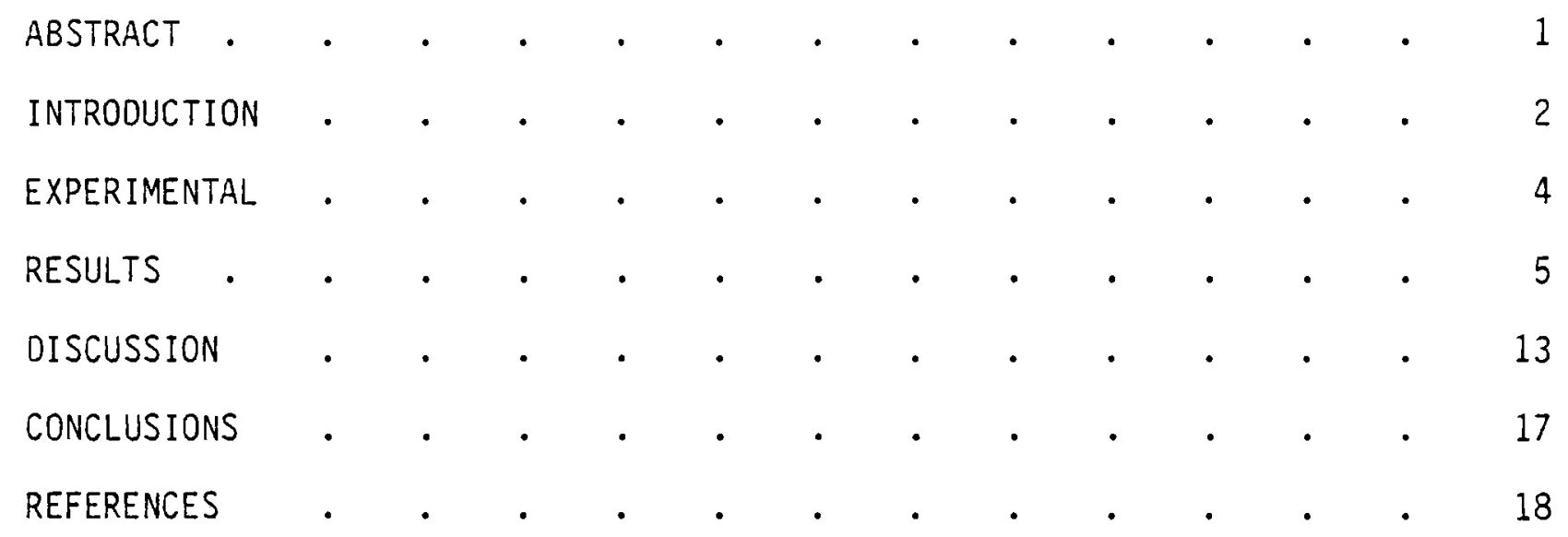




\section{FIGURES}

1 Positive SIMS Spectrum for Various Coals and Coal-like Materials Using a $5 \mathrm{keV}$ Argon Ion Beam in the 12-19 amu Range . .

2 Positive SIMS Spectrum for Various Coals and Coa?-like Materials Using a $5 \mathrm{keV}$ Argon Ion Beam in the 24-30 amu Range ..$\quad$. 7

3 Positive SIMS Spectrum for Various Coals and Coal-like Materials Using a $5 \mathrm{keV}$ Argon Ion Beam in the 36-45 amu Range . . . 8

4 Negative SIMS Spectrum for Various Coals and Coal-iike Materials Using a $5 \mathrm{keV}$ Argon Ion Beam in the 12-19 amu Range . . .

5 Negative SIMS Spectrum for Various Coals and Coal-like Materials Using a $5 \mathrm{keV}$ Argon Ion Beam in the 24-30 amu Range . . . 10

6 Negative SIMS Spectrum for Various Coals and Coal-like Materials Using a $5 \mathrm{keV}$ Argon Ion Beam in the 32-40 amu Range

\section{TABLES}

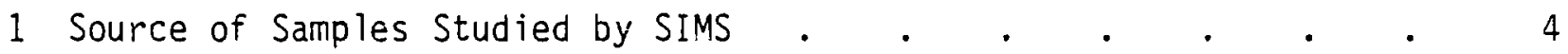

2 Proximate, Ultimate, and Calorific Analysis of Samples . . . 12

3 Distribution of Mineral Matter Impurity Content of the Graphite Sample in Parts per Million and the

Illinois \#6 Sample in Percent of Total Mineral Matter . . . 
STUDY OF COAL STRUCTURE USING SECONDARY ION MASS SPECTROMETRY (a)

\author{
G. L. Tingey, J. M. Lyt le, D. R. Baer, and M. T. Thomas \\ Pacific Northwest Laboratory \\ Richland, Washington 99352
}

\begin{abstract}
$\underline{\text { ABSTRACT }}$
Secondary-ion Mass Spectrometry (SIMS) is examined as a tool for studying the chemical structure of coal. SIMS has potential for analys is of coal because of the following characteristics:

- sensitivity to chemical structure

- high sensitivity to all masses

- application to solids

- excellent depth resolution

- reasonable spatial resolution

SIMS spectra of solid coals show differences with respect to coal rank, the spectra of high rank coal being similar to that of graphite, and the spectra of low rank coal being similar to that of wood. Some functional group analys is is also possible using SIMS. Low rank coals show a larger peak at 15 amu indicating more methyl groups than found in the higher rank coals. Fragments with two and three carbon atoms have also been examined; much larger fragments are undoubtedly present but were not evaluated in this study. Examination of these groups, which are expected to contain valuable information on coal structure, is planned for future work. It has been observed that mineral atoms present in the coal have large secondary ion yields which complicate the interpretation of the spectra. Studies on mineral-free coals and model compounds are therefore recommended to facilitate determination of organic coal structure. In addition, mass spectrometry with much greater mass resolution will aid in distinguishing between various ion species.
\end{abstract}

(a) Work supported by the U.S. Department of Energy under Contract DE-ACO6-76RLO 1830 
INTRODUCTION

For many years scientists have sought information on the molecular structure of coal with only limited success. The large volume of petrographic (Stanton and Finkelman 1979; Kimura 1979; Given and Spackman 1978; Davis, Spackman and Given 1976; Stopes 1919) work, and some very fine work on determining the elemental composition (Tingey and Morrey 1973) of coal, has added greatly to our knowledge, but much of what is published about the molecular structure remains, to a large extent, speculative. In recent years, largely due to the development of new techniques, considerable progress has been made in the study of coal. Of particular interest for determination of molecular structure is recent work using ${ }^{13} \mathrm{C}$ Nuclear Magnetic Resonance (NMR) (Franz et a 1. 1977; Franz 1978; Franz and Skiens 1978; Franz, Camaioni and Skiens 1979; Pugmire et al. 1978; Zilm et a1. 1979; Pugmire et al. 1977; Gerstein et al. 1977a; Gerstein et a1. 1977b) and Fourier Transform Infrared Spectroscopy (FTIR) (Painter and Coleman 1979; Painter et al. 1978a; Painter et al. 1978b; Soloman 1979) techniques. Both of these techniques show considerable promise for clarifying several aspects of the molecular structure, especially where developments permit the analyses on solid coal such as NMR with magic angle spinning ( $\mathrm{Zilm}$ et al. 1979, Gerstein et al. 1977a, Gerstein et a1. 1977b).

In general one who examines coal goes to great lengths to obtain a representative sample. This is done by obtaining a relatively large sample, grinding into a fine powder, and intimately mixing to obtain an average coal sample. Although this approach has proven utility for many studies, it is also important to conduct studies where the inhomogeneity remains and can be directly investigated. This latter approach may give a more accurate evaluation of the actual coal structure as it exists in nature, and may simplify molecular structural studies by providing specific sites for analysis with less complexity than the average coal sample. To fill this need, we have attempted to develop microscopic and surface techniques which can be used directly on solid samples with sufficient resolution to resolve inhomogeneity. 
One such technique is Secondary Ion Mass Spectrometry (SIMS). The purpose of this paper is to report some initial data on SIMS analyses of a variety of coal and coal-like solid materials.

The study of secondary ions generated from ion induced sputtering has a long history dating back to Arnot and Milligan (1936, Arnot and Beckett 1938, Sloane and Press 1938). However, its widespread use as an analytical tool has been developed within the past 10 years. Because the ions which produce the SIMS spectra come only from the outer molecular monolayer of a sample, SIMS is a surface sensitive technique (Benninghoven 1977). The applications of SIMS fall into four general areas (Benninghoven 1977): bulk material analysis by sputter removal of the surface, profiling of thin layers, imaging, and monolayer analysis.

Of particular interest for the analysis of coal is the sensitivity of SIMS to chemical structure. To the extent that clusters of atoms are detected by SIMS, the nature of the atom clusters may reflect the chemical structure of the sample. The mechanisms which produce the secondary ion cluster during sputtering are very complex and subject to intensive research and debate but SIMS has been successfully used to determine chemical structure in several systems (Colton et a1. 1979). For example, characteristic spectra for benzoic acid (Karasek 1974), propane (Dawson 1977), amino acids (Colton et a1. 1979), vitamins (Benninghoven, Jaspers and Sichtermann 1976; Benninghoven and Sichtermann 1977; Benninghoven and Sichtermann 1978), and various drugs (Benninghoven, Jaspers and Sichtermann 1976; Benninghoven and Sichtermann 1977; Benninghoven and Sichtermann 1978) have been observed. In addition, slow sputter rate or static SIMS is frequently used to characterize the various oxidation states observed during initial oxidation of metals (Dawson 1979, Benninghoven et al. 1977). Of particular interest to analysis of coal is the observation that for several organic systems the secondary emission of parent molecular ions have been observed (Colton et al. 1979).

This paper reports SIMS analyses of materials ranging from graphite to wood with several coals of varying rank in between. For this work our efforts have concentrated on species with molecular weights below 50 atomic mass units (amu). Actual spectra are shown which illustrate the type of information which 
can be collected from SIMS analyses. Higher molecular weight fragments were present and undoubtedly will contain valuable information on the structure of coal, and it is our intent to extend our efforts into that area in the future.

\section{EXPERIMENTAL}

The various materials examined in this study including coals, wood, graphite, and polysulfone are listed in Table 1. These materials should yield an orderly variation of structure for examination by SIMS. The samples other than coal were chosen because of their similarity to the structure of coal; wood and graphite are geologic end points in the coalification process. The coal samples were chosen to reflect various stages of coalification such that four distinct coal ranks are represented, that is, in order of increasing rank, brown, lignite, subbituminous, and bituminous.

Slabs one or two millimeters thick and about one-half to one centimeter in cross section were prepared by fracturing a sample with decontaminated tools in a laminar flow hood. This process involves cleaving along natural fracture

TABLE 1. Source of Samples Studied by SIMS

\begin{tabular}{|c|c|c|c|}
\hline Sample & Source & Locality & Index (a) \\
\hline Polysulfone & UDEL (Union Carbide Corp.) & & $A$ \\
\hline Graphite & PGX (Union Carbide Corp.) (b) & & $B$ \\
\hline$H V B^{(C)}$ coal & Ann Lorentz Coal Co. & Buckhannon, WV & C \\
\hline HVB coal & Illinois \#6 Seam & Illinois & 0 \\
\hline$S B(C)$ & Beluga Placer Annex & Ft. Union Coal Field, AK & $E$ \\
\hline Lignite & Knife River Mining Co. & Savage, MO & $F$ \\
\hline Brown coal & Mitsu Bishi Development PTY & Victoria, Austrailia & G \\
\hline Jack Pine & & North Central States & $H$ \\
\hline
\end{tabular}

(a) Identifying index for Figures 1-6

(b) Candidate materials for high temperature gas reactor core supports

(c) HVB - high volatile bituminous SB - subbituminous 
faces or slicing with a knife depending on the type of sample. In this way surfaces were exposed which had limited contact with air and environmental contamination. No effort was made to dry samples previous to the analysis. The samples were mounted on a carousel which in turn was mounted into a vacuum bell and cooled with liquid nitrogen.

A Physical Electronics Industries 545 Scanning Auger Microscope with UTI 100C Quadruple Mass Analyzer based SIMS attachment was used in this study. Argon ions with an energy of $5 \mathrm{keV}$ and a current density of $\sim 10^{-1} \AA / \mathrm{cm}^{2}$ were used as the priamry or sputtering ion beam. The ions were formed by an electron bombardment of 25 milliamperes in an ionization chamber where the argon pressure ranged from 1 to $5 \times 10^{-3} \mathrm{~Pa}$. Usually the ion beam was rastered to cover several $\mathrm{mm}^{2}$ of the sample and the SIMS signals were raster gated to minimize sputter crater edge effects.

Because of the low electrical conductivity of coal, impinging ion beams tend to produce a static charge on the sample which decreases the SIMS signal. In order to minimize this effect and enhance the secondary ion yield, a charge balance is maintained using a compensatory electron stream. Further improvements in secondary ion yields are anticipated as the charge neutralization technique is improved.

RESULTS

SIMS spectra in the 12 to 45 amu region are shown in Figures 1 to 6 for each of the samples listed in Table 1 . Figures 1 to 3 are for the positive SIMS mode, and Figures 4 to 6 are for the negative SIMS mode. The proximate, ultimate, and calorific analysis for the samples are listed in Table 2 and the ash analysis for two of the samples are given in Table 3 . Though results shown in Figures 1 to 6 are not quantitative, the relative peak intensities within a given sample reflect the relative ion yields. Repeats of each scan have been run. Various positions on a given sample of coal differ, mainly in the regions from 23-30 amu and 39-41 amu. These regions are dominated by mineral matter and surface contamination rather than the organic matter in the coal. Other 


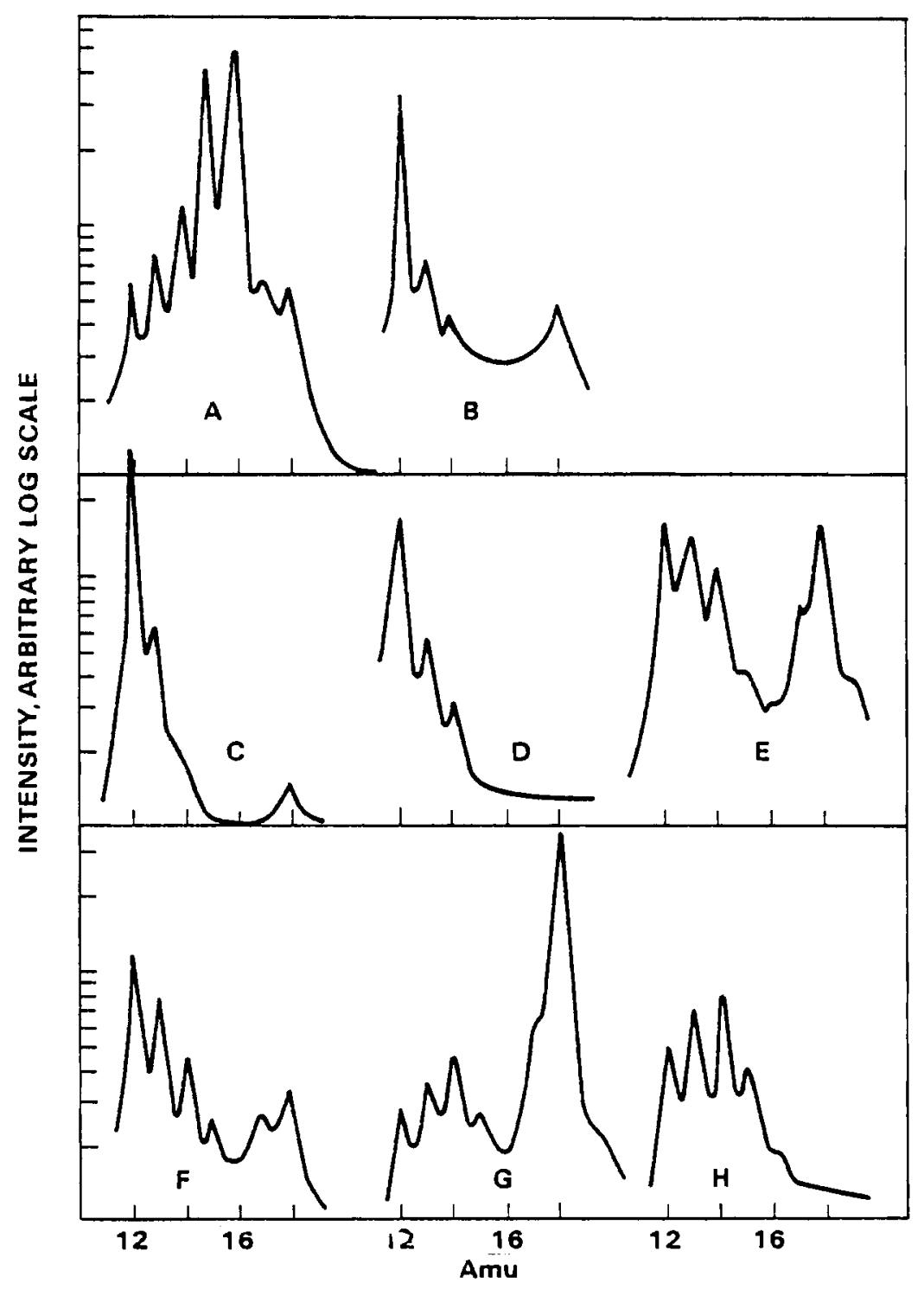

FIGURE 1. Positive SIMS Spectrum for Various Coals and Coal-Like Materials Using a $5 \mathrm{keV}$ Argon Ion Beam in the 12-19 amu Range. A-polysulfone, B-graphite, $C$ and D-high volatile Bituminous coal, E-subbituminous coal, F-lignite, G-brown coal, H-Jack pine, as noted in Table 1. 


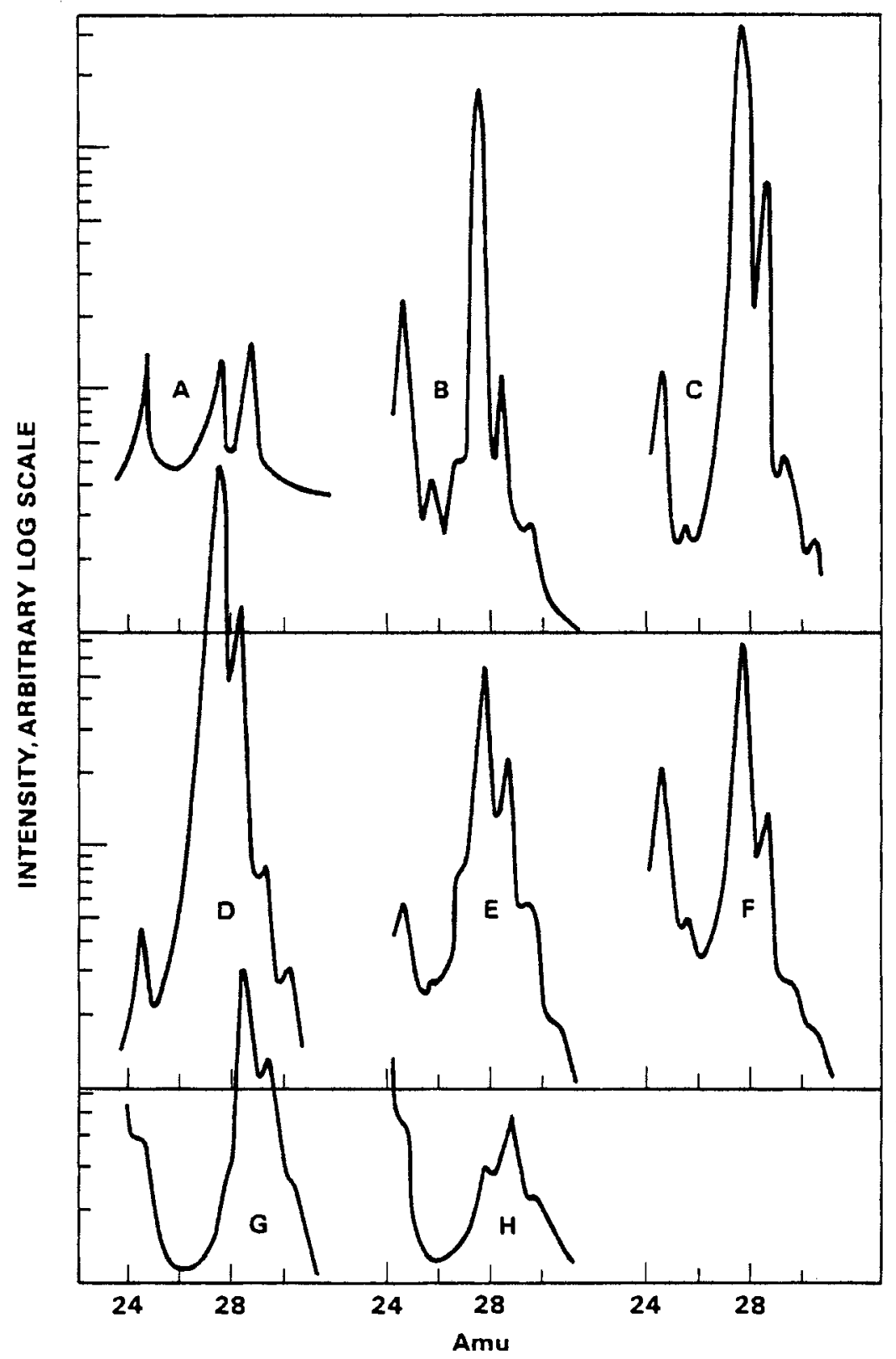

FIGURE 2. Positive SIMS Spectrum for Various Coals and Coal-Like Materials Using a $5 \mathrm{keV}$ Argon Ion Beam in the 24-30 amu Range. Legend as in Figure 1. 


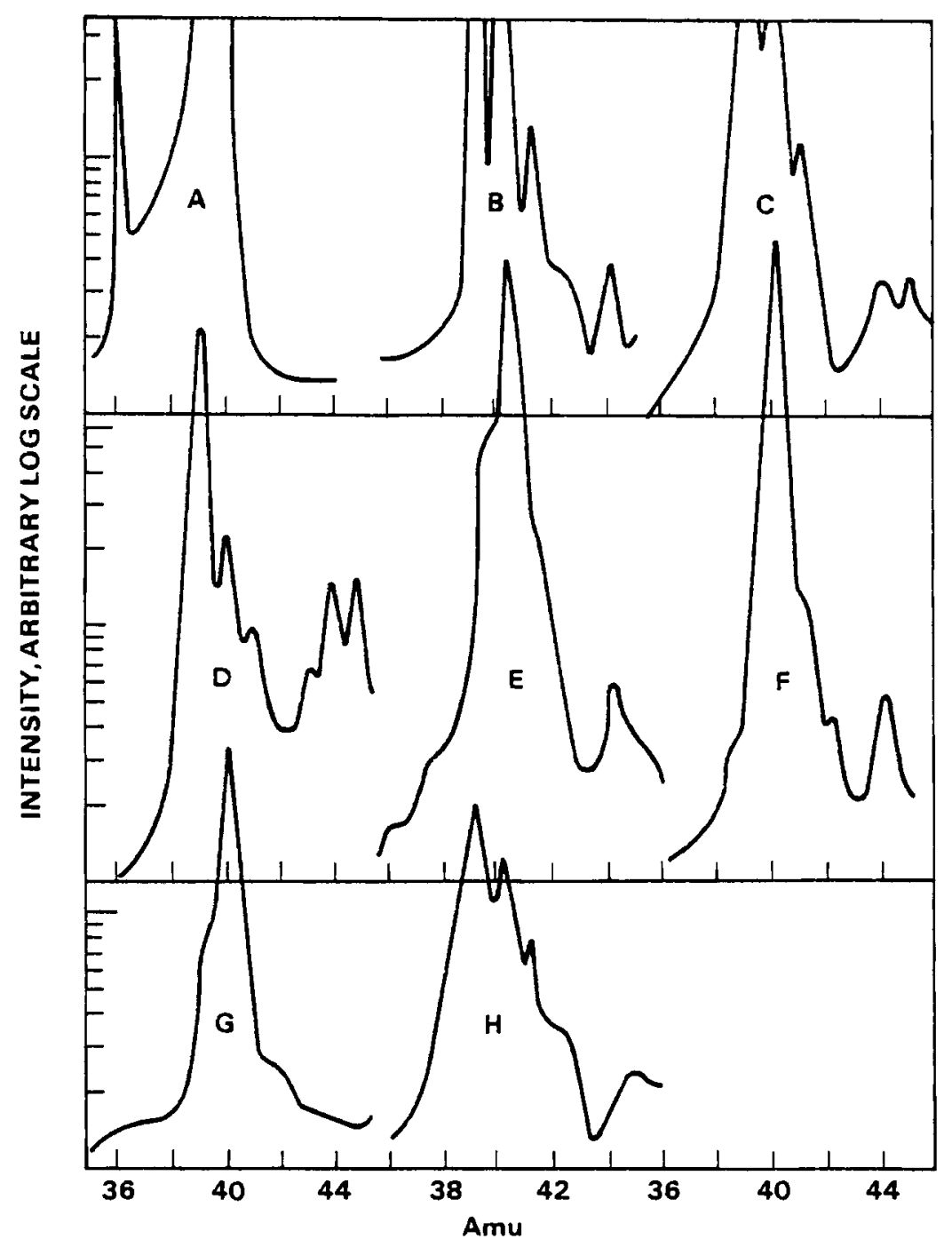

FIGURE 3. Positive SIMS Spectrum for Various Coals and Coal-Like Materials Using a $5 \mathrm{keV}$ Argon Ion Beam in the 36-45 amu Range. Legend as in Figure 1. 


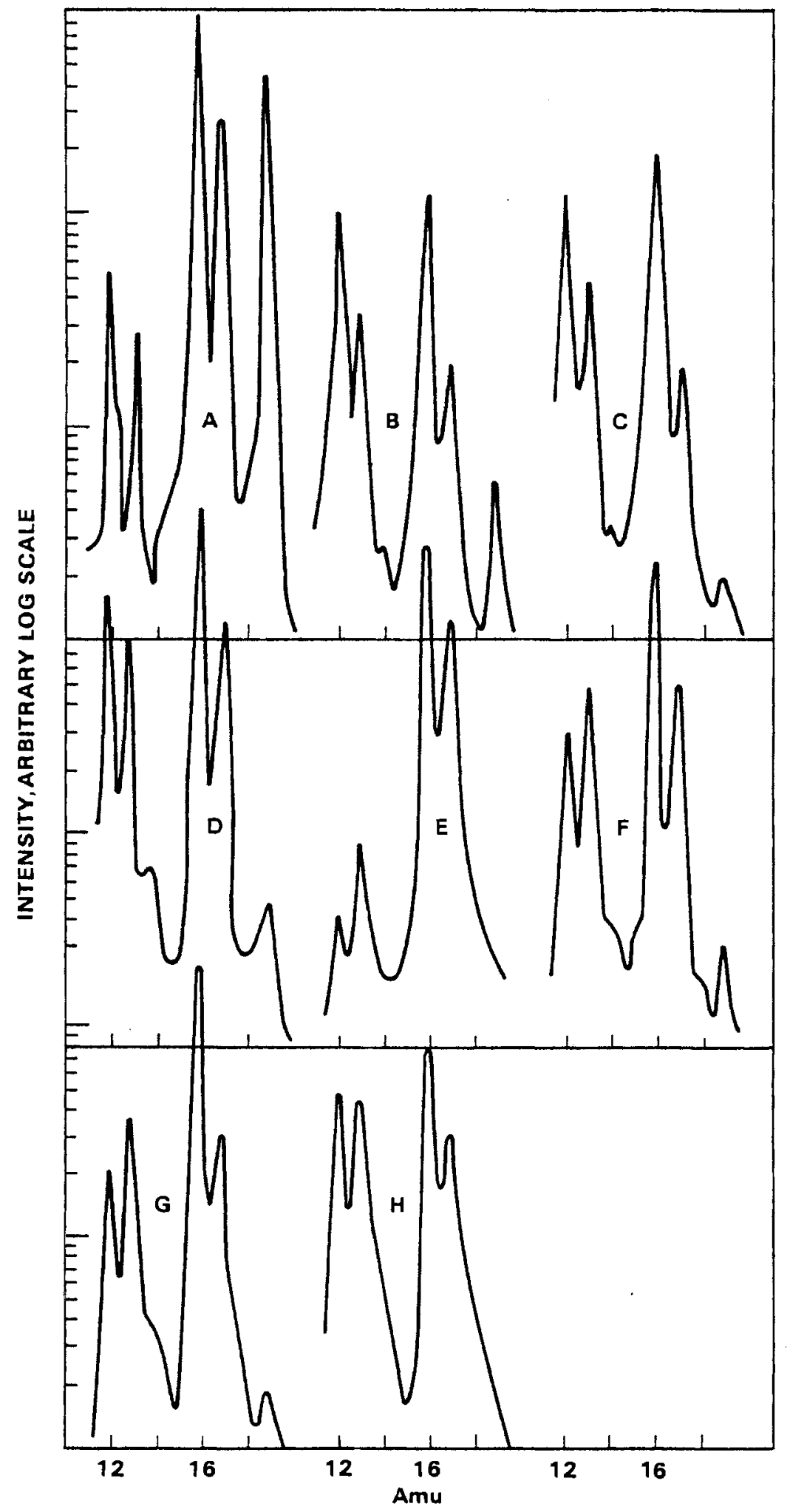

FIGURE 4. Negative SIMS Spectrum for Various Coals and Coal-Like Materials Using a $5 \mathrm{keV}$ Argon Ion Beam in the 12-19 amu range. Legend as in Figure 1. 


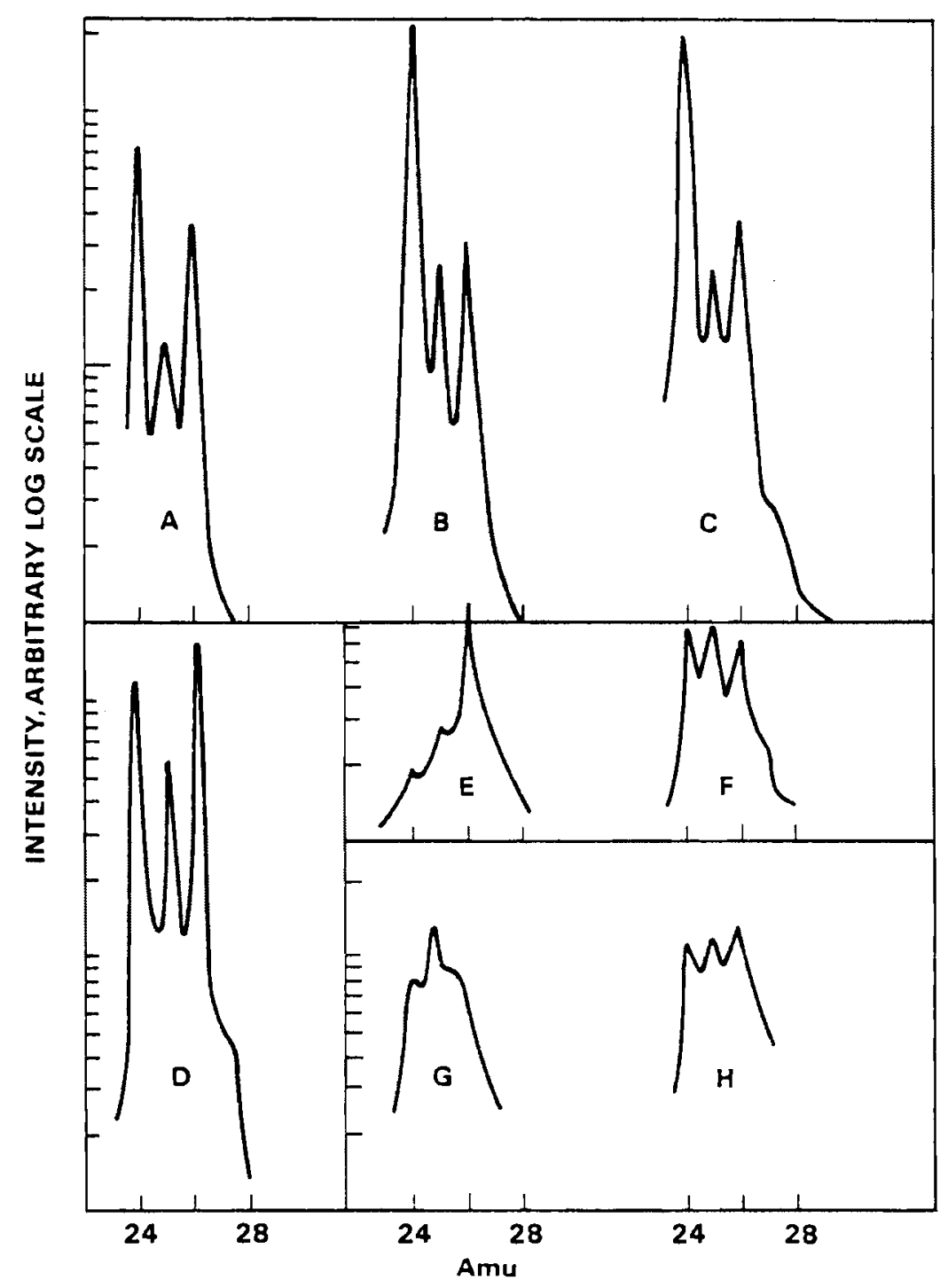

FIGURE 5. Negative SIMS Spectrum for Various Coals and Coal-Like Materials Using a $5 \mathrm{keV}$ Argon Ion Beam in the 24-30 amu range. Legend as in Figure 1. 


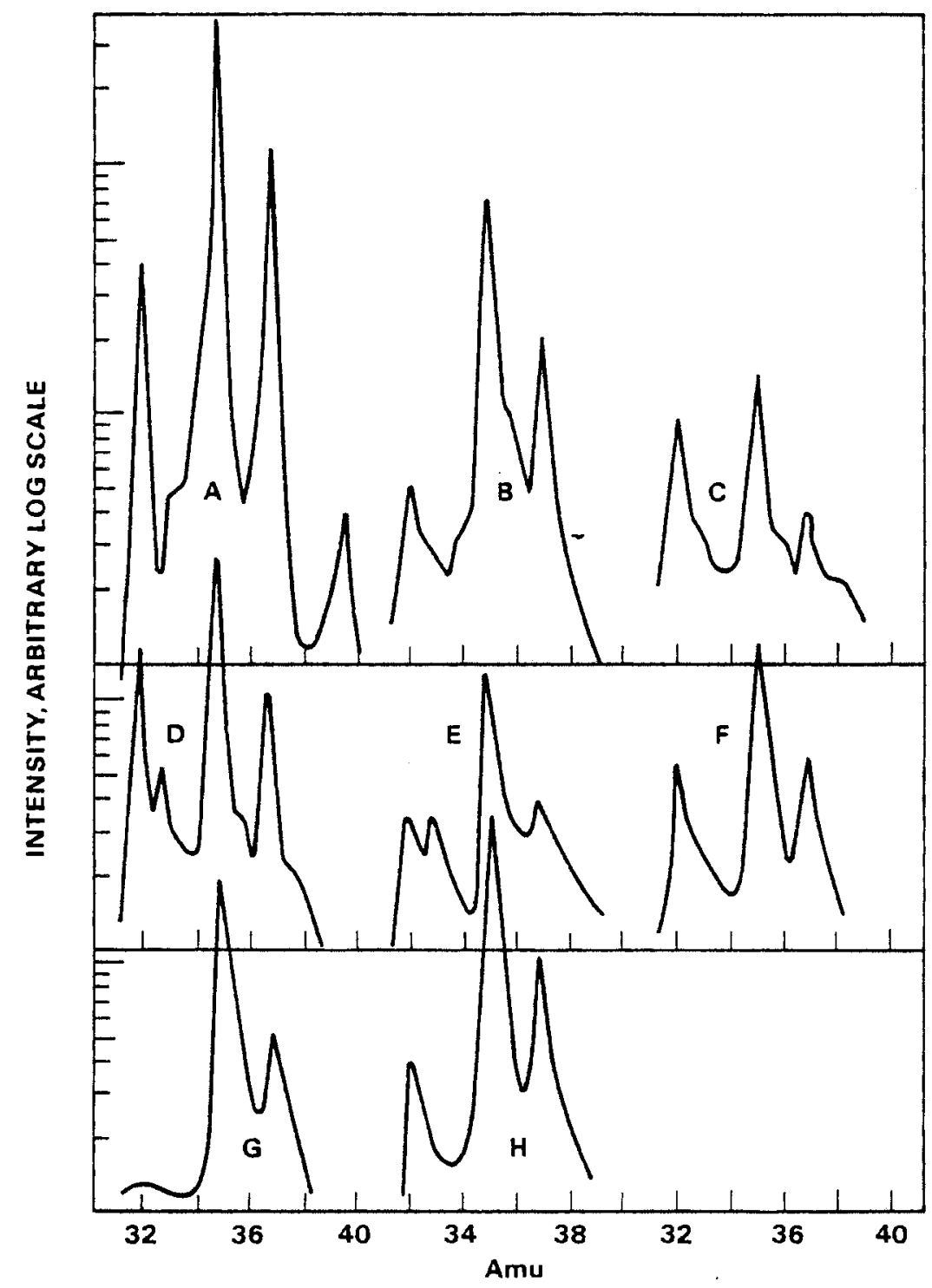

FIGURE 6. Negative SIMS Spectrum for Various Coals and Coal-Like Materials Using a $5 \mathrm{keV}$ Argon Ion Beam in the $32-40$ amu range. Legend as in Figure 1. 
TABLE 2. Proximate, Ultimate, and Calorific Analysis of Samples

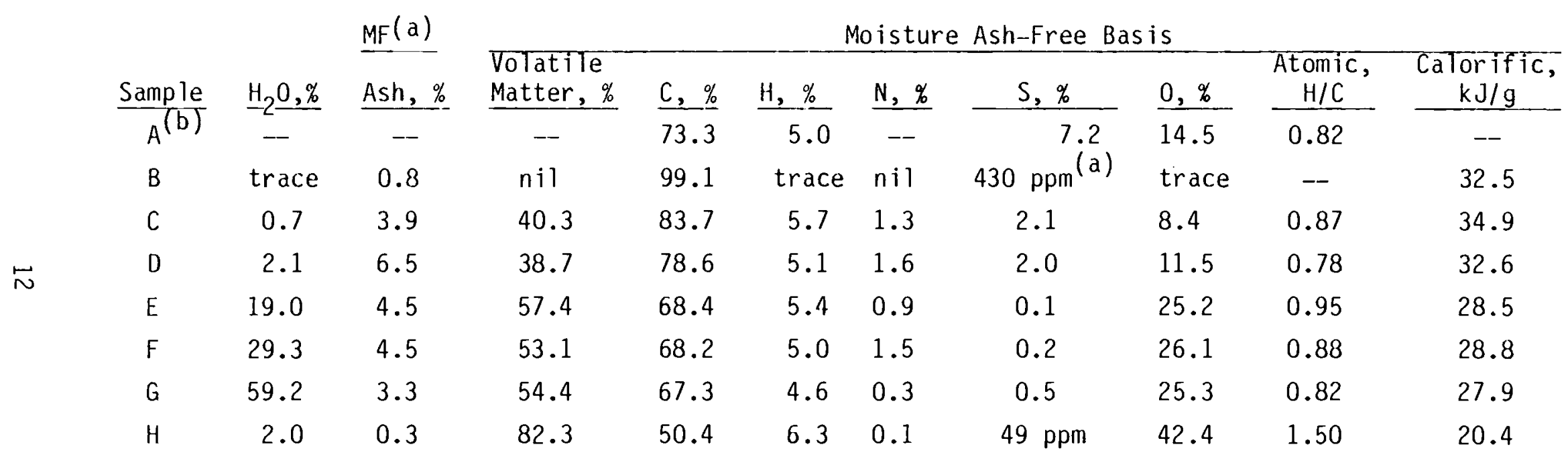

(a) MF - moisture free; ppm - parts per million

(b) Calculated from molecular structure 
TABLE 3. Distribution of Mineral Matter Impurity Content for the Graphite Sample in Parts per Milition and the

I1linois \#6 Sample in Percent of Total Mineral Matter

\begin{tabular}{|c|c|c|c|}
\hline \multirow[b]{2}{*}{ Compound } & \multicolumn{2}{|c|}{ GRAPHITE ${ }^{(a)}$} & \multirow[b]{2}{*}{$\mathrm{ppm}$} \\
\hline & $\mathrm{ppm}$ & Compound & \\
\hline ash & 2779 & $\mathrm{Mg}$ & 20 \\
\hline $\mathrm{s}$ & 430 & $\mathrm{Mn}$ & 40 \\
\hline A1 & 80 & $\mathrm{Na}$ & $<10$ \\
\hline B & 2 & $\mathrm{Ni}$ & 20 \\
\hline $\mathrm{Ba}$ & 40 & $\mathrm{~Pb}$ & $<6$ \\
\hline $\mathrm{Ca}$ & 200 & $\mathrm{Si}$ & 40 \\
\hline $\mathrm{Cu}$ & 20 & $S r$ & $<40$ \\
\hline $\mathrm{Fe}$ & $>1000$ & $\mathrm{Ti}$ & 40 \\
\hline$K$ & $<10$ & V & 20 \\
\hline $\mathrm{Li}$ & 2 & & \\
\hline
\end{tabular}

\begin{tabular}{|c|c|c|c|}
\hline \multicolumn{4}{|c|}{ ILLINOIS $\# 6^{\text {(b) }}$} \\
\hline Compound & Percent & Compound & Percent \\
\hline $\mathrm{Be}$ & 0.84 & $\mathrm{Fe}$ & 19.76 \\
\hline A1 & 5.76 & $\mathrm{Ca}$ & 19.76 \\
\hline $\mathrm{Si}$ & 11.93 & k & 0.55 \\
\hline
\end{tabular}

(a) (Engle 1977)

(b) Done by Schwarzkopf Microanalytical Laboratory, Inc., Woodside, NY.

peaks are reasonably consistent over various positions of the same sample as well as over various samples of the same coal.

\section{DISCUSSION}

Figure 1 shows the 12 to 19 amu positive SIMS data for each sample. Note that a prominent 12 peak is apparent in Figures $1 B, C$, and $D$ but less prominent 
in Figures $1 E, F, G$, and $H$. The prominence of the 12 amu peak corresponds to some extent to the carbon percent as shown by a comparison of the carbon data of Table 2. The prominence of the 13,14, and 15 amu peaks are apparently unrelated to either the percent hydrogen or the hydrogen-carbon ratio in the bulk. These peaks apparently reflect the organic structure of the sample. For example, polysulfone has a repeat structure as follows:

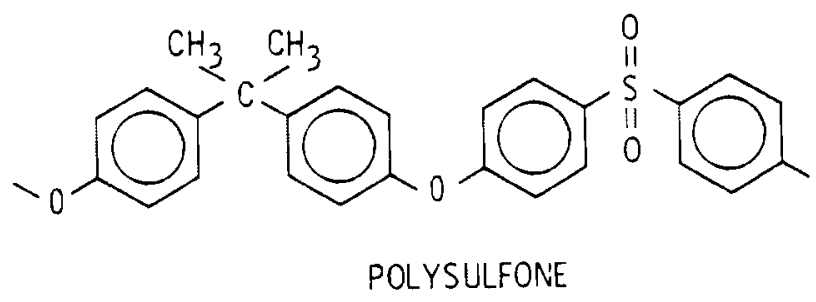

The strong peak at 15 amu shown in Figure $1 \mathrm{~A}$ apparently arises from fission of methyl groups from the tertiary carbon. The 13 and 14 peaks are enhanced by the same structures. The full significance of the 13 and 14 peaks in polysulfone is not immediately clear but may result from cracking of the structure during the sputtering process. However, in other materials these peaks may be enhanced by the presence of $\mathrm{CH}$ or $\mathrm{CH}_{2}$ group in the sample structure. It is apparent that the magnitude of the 13 and 14 peaks decreases as the coal rank increases, as illustrated by $F$ igures $1 C, D, E, F$, and $G$, and the spectra of wood (Figure $1 \mathrm{H}$ ) is the most similar to that of brown coal (Figure 1G). In the lower rank coals and wood the 15 amu peaks are more prominent indicating an increase in methyl structure. The repeat group for cellulose, a major constituent of wood, is (Purves 1954, Sarkanen 1963):

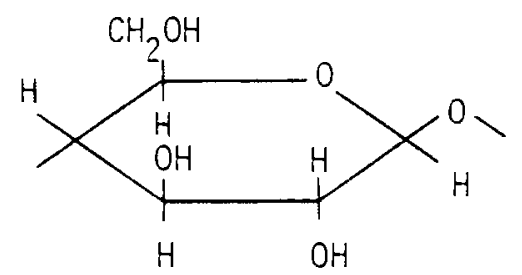

CELLULOSE 
In addition, there are a variety of lignin groups which occur in wood. The postulated structures of lignin vary, but general structural units which are repeatedly postulated are illustrated by the following (Purves 1954, Sarkanen 1963):

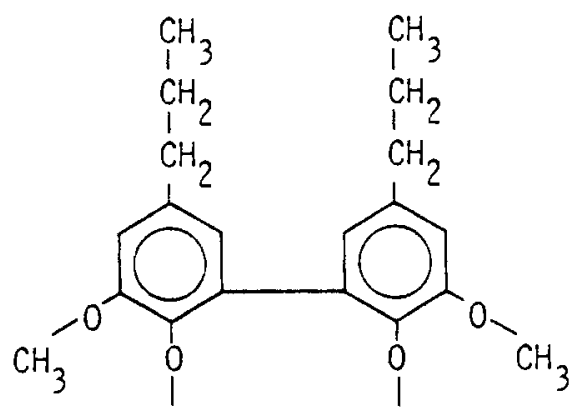

LIGNIN

The existence of linkage involving one or more $\mathrm{CH}_{2}$ units apparently contributes to the increased 14 peaks noted in lower rank coals (Figures $1 E, F$, and $G$ ).

The spectra of graphite (Figure 1B) is most similar to that of the bituminous coals (Figures $1 C$ and $D$ ). This is consistent with the idea that as coal increases in rank its structure becomes more like graphite. The subbituminous and lignite coals yield a SIMS spectra which lies between that of graphite and wood consistent with their structural development during the coalification process.

Peaks in the positive SIMS mode of 24 to 30 amu are shown in Figure 2. Spectra in this area is complicated by the mineral matter constituents of the samples. The dominant peaks of magnesium, aluminum, and silicon are at 24,27 and 28 amu, respectively. There are also significant isotopes at 25 and 26 for magnesium and 29 and 30 for silicon. The isotopic ratios for $\mathrm{Mg}^{25}$ and $\mathrm{Mg} 26$ to $\mathrm{Mg}^{24}$ are 0.129 and 0.144 , respectively. The isotopic ratios for $\mathrm{Si}^{29}$ and $\mathrm{Si}^{30}$ to $\mathrm{Si}^{28}$ are 0.051 and 0.034 , respectively. These mineral matter constituents apparently have a large secondary ion yield and thus dominate the 24 to 30 amu spectra obscuring the detection of $\mathrm{C}, \mathrm{H}, \mathrm{N}$, and 0 complexes in that mass range. Further information in this mass range would require a mass spectrometer with greater mass resolution or the use of materials with mineral matter removed, such as solvent refined coal. 
The positive SIMS spectra of masses 36-45 amu, shown in Figure 3 , contain spectra of both mineral matter constituents and organic matter. The complicated nature of these spectra makes any quantitative evaluation difficult. However, it can be said with certainty that chlorine, potassium, calcium, and perhaps scandium are being sputtered from the samples along with a variety of organic materials. These organic materials consist of two or three carbons and may also include hydrogen and oxygen or nitrogen in the structures. Clearly the use of mineral matter free material will yield a much simpler and thus more interpretable spectra. Such coals, of course, do not exist and materials which have been treated to remove mineral matter may have significantly altered chemical structure due to the treatment. In spite of this drawback, studies of mineral free coal should help to evaluate the potential of the SIMS technique for investigating coal structure.

The ability to observe either positive or negative ion spectra permits flexability which may be helpful in understanding the complicated coal structure. The negative SIMS spectra are shown in Figure 4 to 6 . In Figure 4 showing the 12-19 amu mass region, one can see a noticeable change in the relative peak heights of mass 12 and 13 peaks with change in coal rank. Again high rank coal is similar to graphite, and low rank coal is more similar to wood. In constrast to the positive spectra, the negative SIMS peaks 24,25 , and 26, shown in Figure 5, are indicative of organic structure. It is unlikely that magnesium would be negatively charged to a significant extent and furthermore, the peaks are not present in the proper ratios for the isotopes of magnesium. These peaks indicate two carbon structures and possibly $\mathrm{CN}$. A thorough understanding of the significance relative to the coal structure will require further study. However, it may be noted that the relative amplitude of the 24 to the 25 and 26 peaks generally decreases with coal rank. Again the structure of low rank coals seems to be of a cellulosic and lignitic type with more aliphatic bridges and side chains, while the structure of higher rank coals are more graphitic with larger fused ring systems.

The negative SIMS at 32 to 40 amu is dominated by sulfur and chlorine compounds. Some spectra (especially Figures 60 and E) indicate SH complexes. 
CONCLUSIONS

Although the results of this paper are considered preliminary, several principles have been demonstrated. Included are the following:

1. SIMS mass spectra vary as a function of coal rank.

2. The mass spectra of high rank coals are more similar to graphite, and low rank coals are more similar to wood.

3. Some structural data can be obtained by use of SIMS.

The possible structural information from SIMS includes single and multiple carbon units and heteroatom units. Single carbon units are seen to decrease in hydrogen content as coal rank increases. Methyl, methylene, and methyne groups are more prominent in low rank coals, while carbon with some methyne groups are more prominent in high rank coals. Two carbon units show similar trends with an increased prominence of the $\mathrm{C}_{2} \mathrm{H}$ and $\mathrm{C}_{2} \mathrm{H}_{2}$ with respect to the $\mathrm{C}_{2}$ peaks with a decrease in rank. Sulfur and oxygen complexing with hydrogen were detected but not seen to be a function of coal rank.

It is expected that future results will demonstrate additional principles. Additional structural information will be made available from SIMS as static charging of the sample and the resulting noise is reduced. The basis for the evaluation of SIMS spectra of coal will be broadened by the study of various model compounds and mineral free coal. Mass analysers of greater mass resolution may also be used to avoid the ambiguities of mineral matter constituents. The data will be expanded to include other ion beam energies. Greater spatial resolution may be used to observe chemical heterogeneity in coal.

As yet we have not demonstrated the ability to sputter and analyze high molecular weight species from the coal structure. Indications are that this analysis is possible (Colton et al. 1979). Methods to resolve higher mass regions of the spectra will be studied. If molecules or fragments in the mass region above 100 amu can be observed, the spectra will contain very important structural information. 


\section{REFERENCES}

Arnot, F. L., and C. Beckett. 1938. Proc. R. Soc. A168:103.

Arnot, F. L., and J. C. Milligan. 1936. Proc. R. Soc. A156:538.

Benninghoven, A. 1977. "Surface Analys is by Means of Ion Beams". Chemistry and Physics of Solid Surfaces, Edited by R. Vanselow and S. Y. Tong, CRC Press, Cleveland, $\mathrm{OH}, 207$.

Benninghoven, A., D. Jaspers and W. Sichtermann. 1976. "Secondary-Ion Emission of Amino Acids". App1. Phys. 11:35.

Benn inghoven, A., and W. Sichtermann. 1977. "Secondary Ion Mass Spectrometry. A New Analytical Technique for Biologically Important Compounds". Org. Mass Spectrum 12:595.

Benn inghoven, A., and W. K. Sichtermann. 1978. "Detection, Identification, and Structural Investigation of Biologically Important Compounds by Secondary Ion Mass Spectrometry". Ana1. Chem. 50:1180.

Benninghoven, A., et al. 1977. "Quas is imultaneous SIMS-AES-XPS Investigation of the Oxidation of Titanium in the Monolayer Range". Apply. Phys. Lett. $31: 341$.

Colton, R. J., et al. 1979. "Combined XPS and SIMS Study of Amino Acid Over1ayers". Surf. Sci. 84:235.

Davis, A., W. Spackman and P. H. Given. 1976. "The Influence of the Properties of Coals on their Conversion into Clean Fuels". Energy Sources $3(1): 55-81$.

Dawson, P. H. 1977. "SIMS and EID Observations of Propane Adsorbed on Aluminum". J. Vac. Sci. Technol. 14:786.

Dawson, P. H. and Wing-Chenng Tam. 1979. "The Interaction of Oxygen with Policrystalline Niobium Studied Using AES and Low-Enerjgy SIMS". Surf. Sci. $81: 464$.

Franz, J. A. 1978. "13C, 2 H, 1H N.M.R. and GPC Study of Structural Evolution of a Subbitaminous Coal During Treatment with Tetralin at $427^{\circ} \mathrm{C}$ ". Fue 1 58:405-412.

Franz, J. A., D. M. Camaioni and W. E. Skiens. 1979. "Application of 13C, $2 \mathrm{H}, 1_{\mathrm{H}}$ NMR and GPC to the Study of Structural Evolution of Subbituminous Coal in Tetralin at $427^{\circ} \mathrm{C}$ ". Submitted to the Advances in Chemistry Volume on "Coal Structure". 
Franz, J. A., and W. E. Skiens. 1978. "Side Reactions in the Reductive Alkylation of Low-Rank Coal". Fuel 57:502-504.

Franz, J. A., et al. 1977. "Origin of Certain Heterocyclic Compounds from Depolymerization of Lignite". Fuel 56:366-368.

Engle, G. B. "Properties of Unirradiated HTGR Core Support and Permanent Side Reflector Graphites: PGX, HLM, 2020, and H.440N", General Atomic Report GA-A14328. May 1977.

Gerstein, B. C. et al. 1977a. "Utility of Pulse Nuclear Magnetic Resource in Studying Protons in Coals". J. Phys. Chem. 81(6):565-570.

Gerstein, B. C., et al. 1977b. "High Resolution NMR in Randomly Oriented Solids with Homonuclear Dipolar Broadening: Combined Multiple Pulse NMR and Magic Angle Spinning". J. Chem. Phys. 66(1):361-362.

Given, P. H., and W. Spackman. 1978. "Reporting of Analys is of Low-Rank Coals on the Dry, Mineral-Matter-Free Basis". Fuel 57:319.

Karasek, F. W. 1974. "SIMS (Secondary Ion Mass Spectrometry) Spectra of Organic Compounds". Res./Dev. 25:42.

Kimura, H. 1979. "Petrographic Analysis of the Constituent of Coals and the Properties of Macerals". Nenryo Kyokaishi 58(622):75-89.

Painter, P. C., and M. M. Coleman. 1979. "Application of Fourier Transform Infrared Spectroscopy to the Characterization of Fractionated Coal

Liquids". Fuel 58:301-308.

Painter, P. C., et al. 1978a. "Fourier Transform Infrared Study of Mineral Matter in Coal. A Novel Method for Quantitative Mineralogical Analysis". Fuel $57: 337-344$.

Painter, P. C., et al. 1978b. "Fourier Transform Infrared Study of AcidDemineralized Coal". Fuel 57:125-126.

Pugmire, R. J., et al. 1978. "A Carbon-13 NMR Investigtion of the Chemical Composition of Coal Derived Liquids". Am. Chem. Soc., Div. Fuel Chem., Prepr. 23(2):24-35.

Pugmire, R. J., et al. 1977. "Carbon-13 Magnetic Resonance of Coal-Derived Liquids". Fuel 56:295-301.

Purves, C. B. 1954. "Cellulose and Cellulose Derivatives, Part 1", Edited by E. Ott, H. M. Spurlin, and M. W. Grafflin, Interscience, New York, 66.

Sarkanen, K. V. 1963. "The Chemistry of Wood", Edited by B. L. Browning, Interscience, New York, NY, 259. 
Sloane, R. H., and R. Press. 1938. Proc. R. Soc. A168:284.

Solomon, P. R.. 1979. "Relation Between Coal Structure and Thermal Decomposition Products". Am. Chem. Soc., Div. Fue 1 Chem., Prepr. 24(2):184-195.

Stanton, R. W., and R. B. Finkelman. 1979. "Petrographic Analysis of Bituminous Coa 1: Optical and SEM Identification of Constituents". Scanning Electron Microscopy 1:465-472.

Stopes, M. C. 1919. Proc. Royal Soc. London 908:470.

Tingey, G. L., and J. R. Morrey. 1973. Coal Structure and Reactivity. TID-26637, National Technical Information Service, Oak Ridge, Tennessee.

Zilm, K. W., et al. 1979. "A Comparison of the Carbon-13 N.M.R. Spectra of Solid Coals and their Liquids Obtained by Catalytic Hydrogenation". Fuel 58:11-16. 


\section{DISTRIBUTION}

No. of

Copies

OFFSITE

A. A. Churm

DOE Patent Division

9800 S. Cass Avenue

Argonne, IL 60439

F. D. Stevenson

Basic Energy Science

Department of Energy

Washington, DC 20545

P. C. Scott

Fossil Fuels

Department of Energy

Washington, DC 20545

F. W. Steffgen

Pittsburgh Energy Technology Center

Department of Energy

4800 Forbs Avenue

Pittsburgh, PA 15213

27 DOE Technical Information Center

J. L. Cox

Gas Research Institute

10 West 35 th Street

Chicago, IL 60616

R. D. Macf arlane

Dept. of Chemistry

Texas A\&M University

College Station, TX 77843

L. L. Anderson

Dept. of Mining and Fuels Eng.

University of Utah

Salt Lake City, UT 84112

W. H. Wiser

Dept. of Mining and Fuels Eng.

University of Utah

Salt Lake City, UT 84112
No. of

Copies

P. L. Walker, Jr.

Dept. of Material Science

Pennsylvania State Univ.

University Park, PA 16802

R. E. Wood

TOSCO Corp.

18200 W. Highway 72

Golden, CO 80401

B. C. Gerste in

Chemistry Dept.

Iowa State University

Ames, IA 50011

L. A. Harris

Metals and Ceramics Div.

Oak Ridge National Lab

P.0. Box $X$

Oak Ridge, TN 37830

ONSITE

DOE Richland Operations Office

H. E. Ransom

West inghouse Hanford Company

E. D. Jenson

36 Pacific Northwest Laboratory

D. R. Baer (3)

S. D. Dahlgren

J. A. Franz

C. R. Hann

P. E. Hart

J. M. Lytle (5)

J. R. Morrey

W. E. Skiens

M. T. Thomas (5)

G. L. Tingey (10)

Publishing Coordination (2)

Technical Information (5) 
. 